EPJ Web of Conferences 106, 02002 (2016)

DOI: $10.1051 /$ epjconf/201610602002

(C) Owned by the authors, published by EDP Sciences, 2016

\title{
Characterization of Radiation Fields in Biological Shields of Nuclear Power Plants for Assessing Concrete Degradation ${ }^{a}$
}

\author{
Igor Remec ${ }^{\mathrm{b}}$, Thomas M. Rosseel, Kevin G. Field, and Yann Le Pape \\ Oak Ridge National Laboratory, P.O. Box 2008, Oak Ridge, TN 37831-6170, USA
}

\begin{abstract}
Life extensions of nuclear power plants to 60 and potentially 80 years of operation have renewed interest in long-term material degradation. One material being considered is concrete, with a particular focus on radiation-induced effects. Based on the projected neutron fluence values $(\mathrm{E}>0.1 \mathrm{MeV})$ in the concrete biological shields of the US pressurized water reactor fleet and the available data on radiation effects on concrete, some decrease in mechanical properties of concrete cannot be ruled out during extended operation beyond 60 years. An expansion of the irradiated concrete database and a reliable determination of relevant neutron fluence energy cutoff value are necessary to ensure reliable risk assessment for extended operation of nuclear power plants.
\end{abstract}

\section{Introduction}

Over the last 15 years, more than 70 nuclear power plants (NPPs) in the USA have received approval to extend their licenses to operate up to 60 years. Further extensions, to 80 years and beyond, are being considered to meet future energy demands. The license extension process has renewed the focus on longterm degradation processes in NPP materials. One material currently under consideration is concrete in the biological shields and other structures in NPPs.

It is well known that concrete properties change over time due to slow hydration, crystallization of amorphous components, reactions between cement paste and aggregates, and the effects of the local environment such as humidity, temperature, and for NPP concrete, radiation exposure. In this paper we will concentrate on the effects of radiation.

The effects of radiation on concrete have been addressed in numerous reports, including Clark (1958) [1], Hilsdorf et al. (1978) [2], and Fillmore (2004) [3]. The most often cited is the work by Hilsdorf et al., which concluded that, for some concretes, neutron fluence of $1.0 \times 10^{19} \mathrm{n} / \mathrm{cm}^{2}$ may cause a reduction in compressive and tensile strength and a marked increase in volume. Although it was implied that the effects depend on the neutron fluence being "fast" $(\mathrm{E}>0.1 \mathrm{MeV})$ or "thermal," the report did not

\footnotetext{
a Notice: This manuscript has been authored by UT-Battelle, LLC, under contract DE-AC0500OR22725 with the US Department of Energy. The United States Government retains and the publisher, by accepting the article for publication, acknowledges that the United States Government retains a nonexclusive, paid-up, irrevocable, worldwide license to publish or reproduce the published form of this manuscript, or allow others to do so, for United States Government purposes.

${ }^{\mathrm{b}}$ Corresponding author: remeci@ornl.gov
}

This is an Open Access article distributed under the terms of the Creative Commons Attribution License 2.0, which permits unrestricted use, distribution, and reproduction in any medium, provided the original work is properly cited. 
Table 1. Selected design parameters of the selected PWRs.

\begin{tabular}{|c|c|c|c|c|c|}
\hline Plant & Type & $\begin{array}{c}\text { Thermal } \\
\text { Power }\end{array}$ & PV Thickness & $\begin{array}{c}\text { Thickness of } \\
\text { PV Cavity }\end{array}$ & $\begin{array}{c}\text { Inner Radius of } \\
\text { Biological Shield }\end{array}$ \\
\hline Plant A & 3-loop PWR (W) & $2300 \mathrm{MW}$ & $24.17 \mathrm{~cm}$ & $17.1 \mathrm{~cm}$ & $238.76 \mathrm{~cm}$ \\
\hline Plant B & 2-loop PWR (W) & $1876 \mathrm{MW}$ & $16.84 \mathrm{~cm}$ & $16 \mathrm{~cm}$ & $200.6 \mathrm{~cm}$ \\
\hline
\end{tabular}

offer specifics and did not quantify the effect of the gamma rays. A recent review of Hillsdorf's data by Kontani et al. [4] (2013) revealed that most data at neutron fluences above $3.0 \times 10^{19} \mathrm{n} / \mathrm{cm}^{2}$ were obtained at irradiation temperatures above $100^{\circ} \mathrm{C}$ and were using either aluminous cement or liquid glass aggregate, which is not representative of the environment and materials used in concrete for NPPs.

To address these gaps in the knowledge base, the Light Water Reactor Sustainability (LWRS) program under the US Department of Energy (DOE) has been tasked with establishing a research program on concrete aging and degradation processes in NPPs. Moreover, the work is being performed in partnership with the Electric Power Research Institute (EPRI). This paper outlines recent developments regarding this effort with a focus on the assessment of the radiation environment of concrete biological shields in NPPs.

\section{Radiation Environments in Concrete Biological Shields of NPPs}

Radiation-induced degradation of concrete has been historically correlated to neutron fluence and gamma-ray dose. Therefore, estimates of the bounding fluence and dose values for the fleet of US NPPs for the projected extended service, 80 years (or beyond), are needed. This is by itself a significant task given the substantial design differences among NPPs manufacturers and variation in plants operations. In addition, no routine monitoring of radiation fields in biological shields has been established. However, every operating NPP is required to implement a reactor pressure vessel (RPV) surveillance program, and a wealth of information from these programs is publicly available from ADAMS [5]. To capitalize on this information, we implemented a two-pronged approach: (a) a search of ADAMS database was performed to collect data from the RPV surveillance programs, and (b) coupled neutron and gamma-ray transport calculations were performed for two selected pressurized water reactors (PWRs) to provide guidelines on how to extrapolate the pressure vessel flux/fluence data to the flux/fluence in the concrete of the biological shield. Although the initial plan was to review data from the cavity dosimetry programs, which were implemented at numerous NPPs, this approach was not pursued because these results are not in ADMAS database and are not readily or publicly available. However, for the two PWR selected for the analyses the cavity dosimetry results were available.

\subsection{Radiation Transport Simulations}

The radiation transport calculations were performed for one three-loop and one two-loop PWR. The PWRs were given preference over the boiling water reactors (BWRs) because the latter typically exhibit lower neutron fluence levels in the ex-vessel region than the PWRs. Among the PWR designs, it was expected that the highest neutron flux levels outside the RPV would appear in two-loop plants followed by lower flux levels in three-loop plants and the lowest levels in four-loop plants. This was later confirmed by the survey of the ADAMS data performed by Esselman and Bruck (2013) [6]. Some relevant design characteristics of the two plants that were analyzed are listed in Table 1.

The computer models of the two plants were developed previously for benchmarking of the radiation transport calculation methodology for the light water reactor RPV surveillance programs and for investigations of the RPV neutron exposure (Remec and Kam (1997) [7]; Remec (1999) [8]), and were only modified to include or increase the extent of the biological shield. 
The transport calculations were performed using the DORT computer code from the DOORS3.2a code system, which includes one-, two-, and three-dimensional (1-D, 2-D, and 3-D) discrete-ordinates neutron and photon transport codes [9]. The flux synthesis method was used, which relies on 2-D and 1-D transport calculations to estimate the neutron fluxes in the 3-D geometries. The synthesis method remains the de facto state-of-the-art method used in nuclear industry for calculating neutron fluxes for RPV surveillance programs. However, a 3-D deterministic transport codes (Rhoades (1997) [10]; Evans et al. (2010) [11]) or hybrid deterministic Monte Carlo methods (Mosher et al. (2013) [12]) are available and could be used in future analyses.

The neutron and gamma-ray cross sections were taken from the latest of the BUGLE-series libraries, namely, BUGLE-B7, which is a 47-neutron and 20-gamma-ray multigroup library based on ENDF/BVII.0 nuclear data (Risner et al. (2011) [13]). The P3 approximation to the angular dependence of the anisotropic scattering cross sections (i.e., the P0 to P3 Legendre components) was taken into account, and a symmetric S8 "directional quadrature set" (i.e., a set of discrete directions and angular quadratures) was used for all transport calculations.

The simulations provided multigroup neutron and gamma-ray fluxes throughout the reactor, RPV, and the biological shield, which were used to determine neutron fluxes, dose rates, heating rates, and reaction rates. The updated cross sections resulted in only minor changes in results with respect to the previous analyses. Good agreement, typically within 10\%, was observed between the calculated reaction rates and measured reaction rates in the cavity between the RPV and biological shield for the neutron threshold dosimeters ${ }^{238} \mathrm{U}(\mathrm{n}, \mathrm{f}),{ }^{58} \mathrm{Ni}(\mathrm{n}, \mathrm{p}),{ }^{54} \mathrm{Fe}(\mathrm{n}, \mathrm{p}),{ }^{46} \mathrm{Ti}(\mathrm{n}, \mathrm{p}),{ }^{63} \mathrm{Cu}(\mathrm{n}, \alpha)$, therefore confirming the validity of the calculations. However, no measurements with gamma-ray sensitive monitors were available for benchmarking.

\subsection{Results from the Radiation Transport Simulations}

The variation of the neutron and gamma-ray flux with the radial distance from the core center, through the RPV, cavity, and concrete shield is shown in Fig. 1 for the three-loop plant. The shapes of the flux distributions for the two-loop and three-loop plants are quite similar. Neutron fluxes for all energies, except the thermal neutron flux, exhibit a monotonic decrease through the RPV, cavity, and inside the concrete shield. However, the rate of attenuation varies depending on the material. For example, the decrease is large in the RPV steel and in the biological shield concrete but very small through the air in the cavity region. The gamma-ray flux shows similar behavior. However, thermal neutron flux $(\mathrm{E}<0.41 \mathrm{eV})$ behaves remarkably different: the "U" shape in the RPV wall indicates that thermal neutrons penetrate into the wall from both surfaces, due to the higher thermal flux levels in the water coolant inside the RPV and in the concrete outside the RPV. From the outer wall, the thermal flux increases in the outward direction and reaches local maximum about $8-10 \mathrm{~cm}$ (3-4 in.) inside the concrete wall. The local thermal flux maximum inside the concrete wall is caused by strong downscattering of higher energy neutrons in concrete.

The variations in radiation field with vertical distance from the core midplane are relatively minor in the large section close to the reactor beltline and will not be shown here. The variations with azimuthal position along the selected radial distance from the core vertical axis are also relatively modest; however, they are largely affected by the presence of the ex-vessel detector cavities.

Detailed comparison of the fluxes at the RPV wall and inside the concrete shield for the twoloop and three-loop PWR are given in Table 2. The maximum neutron fluxes $(\mathrm{E}>1 \mathrm{MeV}$ and $\mathrm{E}$ $>0.1 \mathrm{MeV}$ ) at the RPV outer radius are 20-30\% higher than the maximum fluxes in concrete. The fluxes, determined at the maximum at the RPV wall, are typically provided in RPV surveillance reports. They can be used as conservative estimates for the fluxes in concrete shields or for screening purposes. 


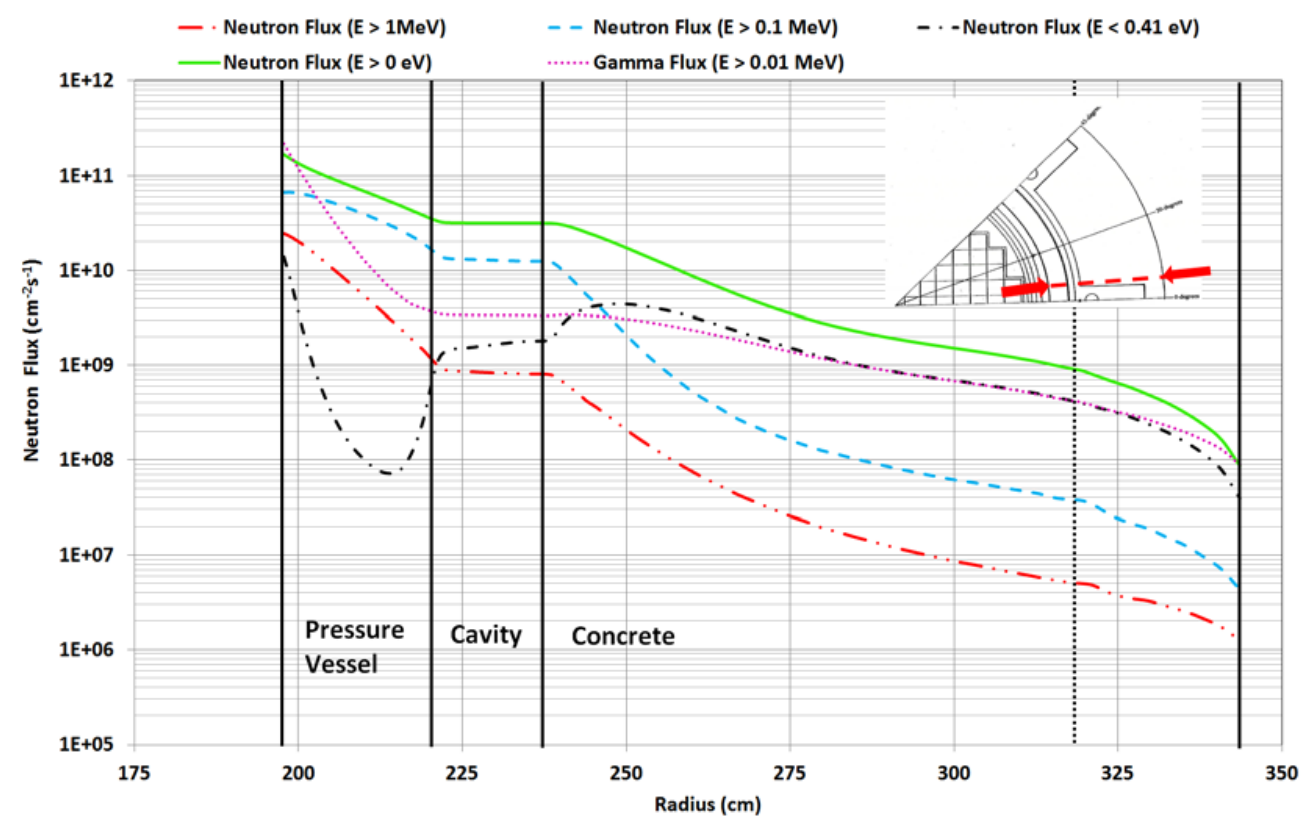

Figure 1. Neutron and gamma-ray flux versus distance from the core for the three-loop PWR plant. The insert shows the location of the radial segment plotted on the abscissa. Different curves depict fluxes with energies above the threshold energy given in parentheses. The dotted vertical line at the right side of the plot marks the outer edge of the detector well.

The total neutron and gamma fluxes at the RPV outer wall agree within $\sim 10 \%$ with the maximum values in concrete. The exception is the thermal neutron flux, which is $50-100 \%$ higher in the concrete. Thermal flux is subject to large local variations, depending on the local material.

For determination of the location of maximum flux in the biological shield, the concrete shield shape (e.g., location of ex-core detector cavities) must be taken into account. A simple rule appears to be that the maximum heating rate and maximum fluxes in concrete will appear in the concrete segment located closest to the position of the maximum flux on the RPV outer wall.

It was also observed that the two-loop and three-loop PWRs have quite similar neutron and gammaray spectra in the cavity region; however, the two-loop plant analyzed has two to four times higher neutron and gamma fluxes and heating than the three-loop plant considered.

Inside the concrete of the biological shield, the neutron spectrum varies significantly with the distance from the inner surface, as is shown in Fig. 2 for the three-loop plant.

Based on data in Table 2, the predicted maximum neutron fluences in the concrete shield at 40,60 and 80 years of operation, assuming 92\% capacity factors, are listed in Table 3.

\section{Assessment of Concrete Degradation}

The assessment of the radiation-induced degradation of concrete in NPP biological shields is based on the fluences determined in Sect. 2 and data obtained from a recently completed comprehensive review of the literature on irradiated concrete (Field et al. (2014)) [14]. Figure 3 depicts the ratio of the compressive strength of irradiated concrete to compressive strength of unirradiated concrete versus neutron fluence. Vertical dashed lines in Fig. 3 show the projected neutron fluence $(\mathrm{E}>0.1 \mathrm{MeV})$ in the biological shield of a two-loop PWR and indicate that some degradation of concrete may be possible, 


\section{$15^{\text {th }}$ ISRD}

Table 2. Summary and comparison of neutron and gamma fluxes and heating rates in three-loop and two-loop PWRs.

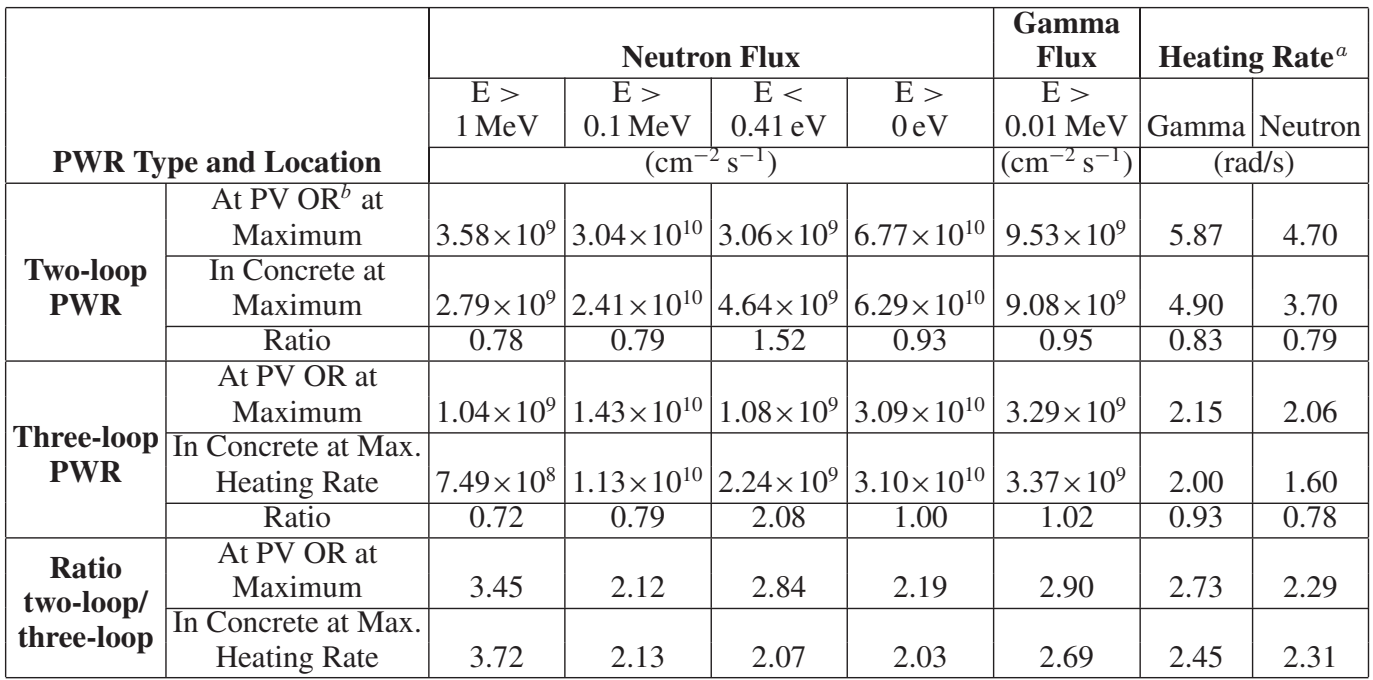

${ }^{a}$ Heating rates at the RPV outer radius are calculated with flux-to-dose conversion factors for concrete even though the actual material at that location is air. This was done to allow easier comparison with heating rates in the biological shield.

${ }^{b} \mathrm{PV}$ OR indicates pressure vessel outer radius.

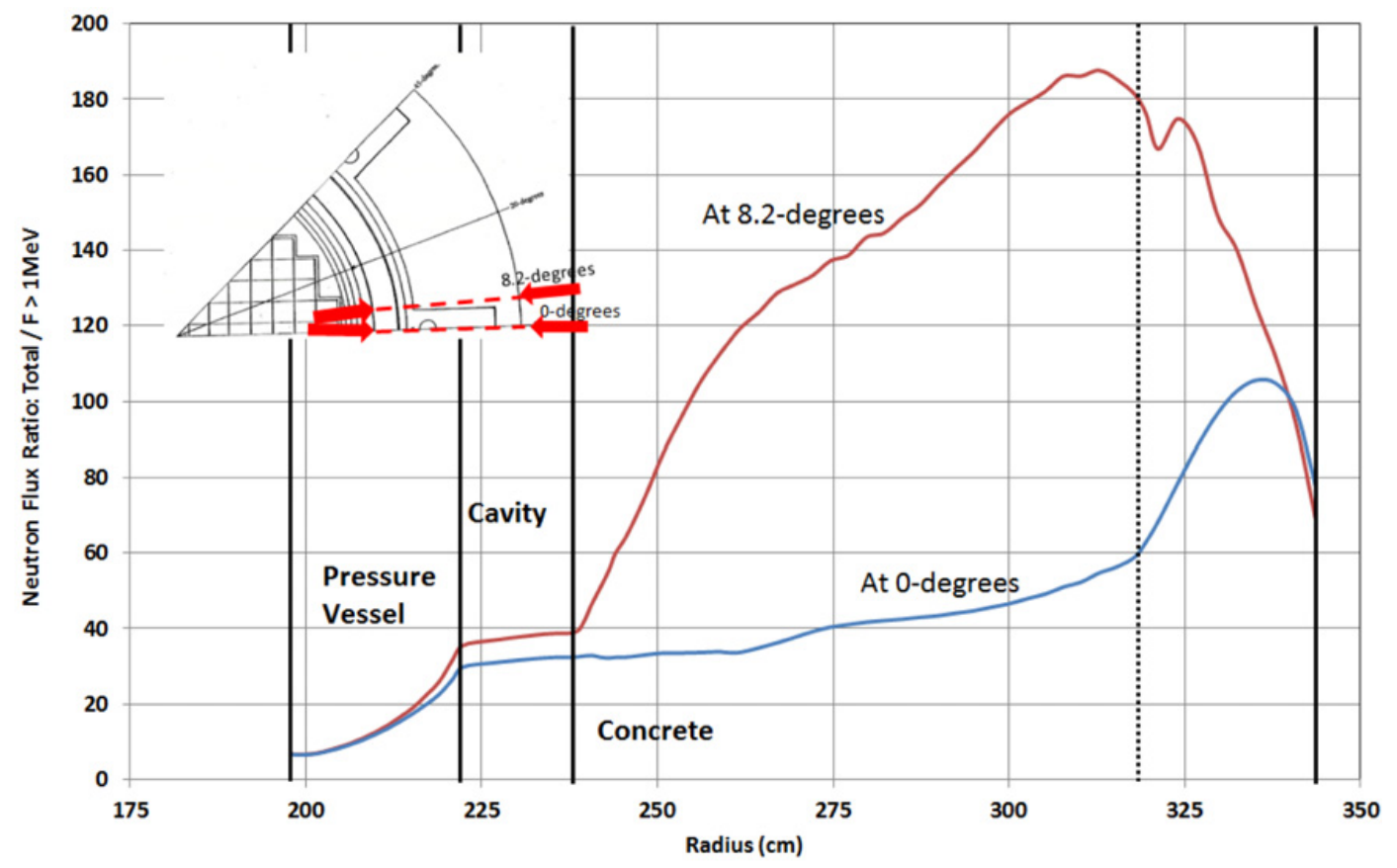

Figure 2. Ratio of total-to-fast $(\mathrm{E}>1 \mathrm{MeV})$ neutron flux versus distance from the core for the three-loop PWR. The insert shows the location of the radial segments plotted on the abscissa. Vertical lines depict the boundaries between RPV, cavity, and concrete; the dotted vertical line marks the radial location of the ex-core detector well wall farther away from the core. 
Table 3. Predicted neutron fluence for the two PWRs analysed at 40, 60, and 80 years of operation assuming a $92 \%$ capacity factor.

\begin{tabular}{|c|c|c|c|c|}
\hline \multirow{2}{*}{ Years of Operation } & \multirow{2}{*}{ PWR Type } & \multicolumn{3}{|c|}{ Neutron Fluence (n/cm $\mathbf{c}^{\mathbf{2}}$} \\
\cline { 2 - 5 } & & $\mathrm{E}>0.0 \mathrm{MeV}$ & $\mathrm{E}>0.1 \mathrm{MeV}$ & $\mathrm{E}>1.0 \mathrm{MeV}$ \\
\hline \multirow{2}{*}{40} & 2-loop & $7.3 \times 10^{19}$ & $2.8 \times 10^{19}$ & $3.2 \times 10^{18}$ \\
\cline { 2 - 5 } & 3-loop & $3.6 \times 10^{19}$ & $1.3 \times 10^{19}$ & $8.7 \times 10^{17}$ \\
\hline \multirow{2}{*}{60} & 2-loop & $1.1 \times 10^{20}$ & $4.2 \times 10^{19}$ & $4.9 \times 10^{18}$ \\
\cline { 2 - 5 } & 3-loop & $5.4 \times 10^{19}$ & $2.0 \times 10^{19}$ & $1.3 \times 10^{18}$ \\
\hline \multirow{2}{*}{$\mathbf{8 0}$} & 2-loop & $1.5 \times 10^{20}$ & $5.6 \times 10^{19}$ & $6.5 \times 10^{18}$ \\
\cline { 2 - 5 } & 3-loop & $7.2 \times 10^{19}$ & $2.6 \times 10^{19}$ & $1.7 \times 10^{18}$ \\
\hline
\end{tabular}

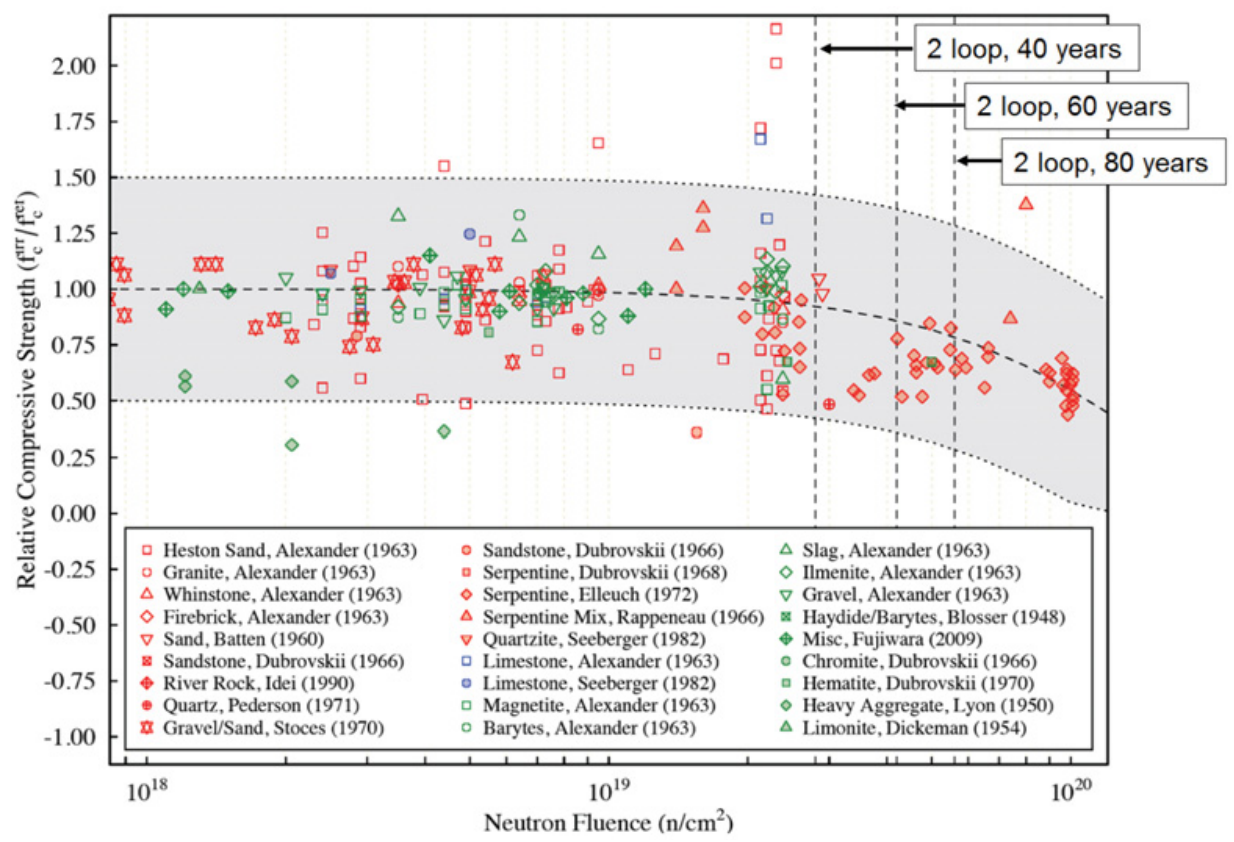

Figure 3. Relative compressive strength of concrete versus neutron fluence. Vertical dashed lines indicate expected neutron fluence $(\mathrm{E}>0.1 \mathrm{MeV})$ for a two-loop PWR. Figure modified from Ref. 14 for publication here.

in particular during extended operation up to 80 years. Similar degradation trends were observed for the concrete tensile strength (albeit more pronounced) and the modulus of elasticity [14].

A projection based on the review of ADAMS database [5] indicated that practically all the PWRs in US fleet, at 80 years of operation, will exceed the $1.0 \times 10^{19} \mathrm{n} / \mathrm{cm}^{2}$ neutron fluence $(\mathrm{E}>0.1 \mathrm{MeV})$, with the upper bound value estimated to be $\sim 6 \times 10^{19} \mathrm{n} / \mathrm{cm}^{2}$. BWRs, however, will stay below the $1.0 \times 10^{19} \mathrm{n} / \mathrm{cm}^{2}$ neutron fluence.

One notable feature in Fig. 3 is the large variation in residual compressive strength at any given neutron fluence value. The scattering of data, which are assembled from a large number of independent experiments, is caused by variations in numerous factors, such as different types of cement and aggregate, different cement-to-water ratios, different specimen sizes, variation in concrete curing and thermal treatment, and different temperatures of specimens during irradiation.

One parameter, however, is of particular interest: the reported "neutron fluence" varies greatly between experiments. Some experiments gave only qualitative descriptions such as "slow" or "fast" neutron fluence, some used fluence of neutrons at energies above $0.1 \mathrm{MeV}$, and some above $1.0 \mathrm{MeV}$, 


\section{$15^{\text {th }}$ ISRD}

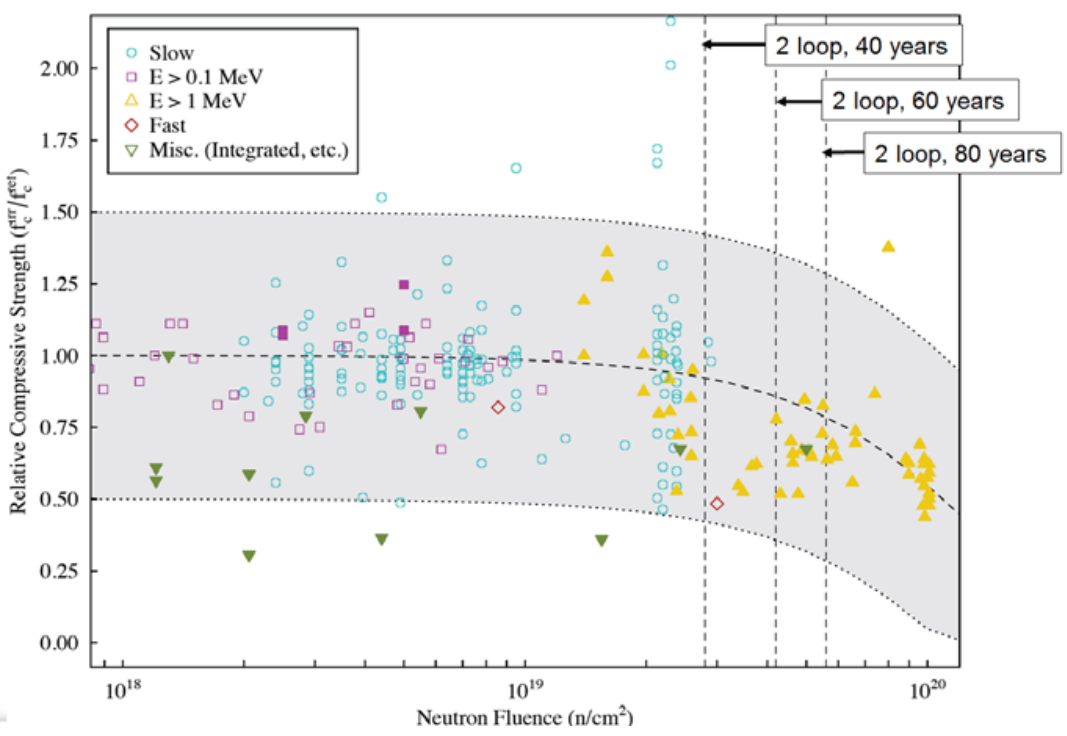

Figure 4. Relative compressive strength of concrete versus neutron fluence. The shapes of the symbols indicate neutron fluence energy cutoff. Solid symbols indicate specimen temperature during irradiation was above $100^{\circ} \mathrm{C}$; hollow symbols correspond to temperature below $100^{\circ} \mathrm{C}$. The fluence $(\mathrm{E}>0.1 \mathrm{MeV})$ values for the two-loop PWR are shown as dashed vertical lines.

some reported total $(\mathrm{E}>0 \mathrm{MeV})$ fluence, and some experiments did not address the energy of neutrons at all. The neutron spectrum was actually provided only for a few experiments. This is illustrated in Fig. 4, in which the data from Fig. 3 are shown again, but the symbols denote the energy "cutoff" of neutron fluence. The lack of segregation of data points corresponding to different neutron fluence energy cutoff levels in Fig. 4 prevents a determination of the energy value relevant for radiation-induced degradation of concrete. Due to the potentially large variations in neutron spectrum between experiments and even between different locations in the same irradiation, as illustrated in Fig. 2, it is not possible to "re-normalize" the database to a common denominator, such as fluence $(\mathrm{E}>0.1 \mathrm{MeV})$.

Despite not being able to normalize the data to a unique cutoff, the neutron fluence cutoff value is crucial for the assessment of concrete degradation in NPPs. The values listed in Table 3 indicate that both plants remain below the $1.0 \times 10^{19} \mathrm{~cm}^{-2}$ fluence value for the cutoff $1 \mathrm{MeV}$, and therefore no radiationinduced degradation would be expected even for the 80 years of operation. However, for the $0.1 \mathrm{MeV}$ cutoff, both plants exceed the $1.0 \times 10^{19} \mathrm{~cm}^{-2}$ fluence level during 40 years of operation, and some concrete degradation may be expected. This is even more pronounced if the degradation assessment is based on the integral fluence $(\mathrm{E}>0 \mathrm{MeV})$.

It should be pointed out that the fluence values listed in Table 3 and shown for the two-loop plant in Fig. 3 correspond to the maximum neutron fluence $(E>0.1 \mathrm{MeV})$ values in the shield, which appear on the inner surface of the shield. The fluence $(E>1 \mathrm{MeV})$ rapidly decreases inside the shield and falls by an order of magnitude in the first $25 \mathrm{~cm}$. This indicates that radiation-induced concrete degradation, if present, will likely be limited to a shallow region of the biological shield close to the inner surface and may not be important for the structural performance of the biological shield.

Another observation related to Fig. 4 is that the data points at the high fluence end are dominated by the data reported for the energy cutoff of $1 \mathrm{MeV}$. If the data are reported for the cutoff energy of $0.1 \mathrm{MeV}$, the data would move to significantly higher (approximately an order of magnitude) fluences, resulting in a reduced prediction of radiation degradation in the $1-10 \times 10^{19} \mathrm{~cm}^{-2}$ fluence range. 
Based on a recent assessment, it appears that neutron-induced defects in the aggregate phase and the resulting radiation-induced volumetric expansion are the dominant mechanism for the degradation of mechanical properties of concrete under irradiation $[14,15]$. For that reason, not much attention is given to the gamma-ray fields in this paper. These fields should be addressed in planning accelerated irradiation experiments, at least from the perspective of specimen heating and temperature control. To keep the focus of this paper on the issue of neutron fluence cutoff, discussion of the other effects, such as variations in aggregates and water content of the concrete, was deliberately avoided; some of these aspects were addressed elsewhere [16].

\section{Conclusion}

Based on projected neutron fluence values $(\mathrm{E}>0.1 \mathrm{MeV})$ in the concrete biological shields of the US PWR fleet and data available on the effect of radiation on concrete, some decrease in the mechanical properties of concrete cannot be ruled out during extended operation beyond 40 years. An expansion of the irradiated concrete database and reliable determination of relevant neutron fluence energy cutoff value are necessary to ensure reliable risk assessment for extended operation of NPPs.

\section{References}

[1] R. Clark, Radiation Damage to Concrete, Technical Report HW-56195, General Electric, Hanford Laboratories, Richland, WA (1958)

[2] H. Hilsdorf, J. Kropp, H. Koch, The effects of nuclear radiation on the mechanical properties of concrete, Special Publication of the American Concrete Institute 55, 223-254 (1978)

[3] D. Fillmore, Literature Review of the Effects of Radiation and Temperature on the Aging of Concrete, Technical Report INEEL/EXT-04-02319, Idaho National Engineering and Environmental Laboratory (2004)

[4] O. Kontani, Y. Ichikawa. A. Ishizawa, M. Takizawa, O. Sato, Irradiation effects on concrete structure, International Symposium on the Ageing Management and Maintenance of Nuclear Power Plants, 173-182 (2010)

[5] U.S. NRC Agencywide Documents Access and Management System (ADAMS), http://www.nrc.gov/reading-rm/adams.html

[6] T. Esselman and P. Bruck, Expected Condition of Concrete at Age 80 Years of Reactor Operation, Technical Report A13276-R-001, Lucius Pitkin, Inc. (2013)

[7] I. Remec, F. Kam, H.B. Robinson-2 Pressure Vessel Benchmark, Technical Report ORNL/TM13204, Oak Ridge National Laboratory (1997)

[8] I. Remec, Study of the Neutron Flux and Dpa Attenuation in the Reactor Pressure-Vessel Wall, Technical Report ORNL/NRC/LTR-99/5, Oak Ridge National Laboratory (1999)

[9] DOORS3.2a: One, Two- and Three-Dimensional Discrete Ordinates Neutron/Photon Transport Code System, RSICC Code Package CCC-650

[10] W. Rhoades, The TORT Three-Dimensional Discrete Ordinates Neutron/Photon Transport Code (TORT Version 3), Technical Report ORNL/TM-13221, Oak Ridge National Laboratory (1997)

[11] T. Evans, A. Stafford, R. Slaybaugh, K. Clarno, Denovo, A New Three-dimensional Parallel Discrete Ordinates Code in SCALE, Nuclear Technology 171, 171-200 (2010)

[12] S.W. Mosher, A.M. Bevill, S.R. Johnson, A.M. Ibrahim, C.R. Daily, T.M. Evans, J.C. Wagner, J. O. Johnson, R.E. Grove, ADVANTG-An Automated Variance Reduction Parameter Generator, ORNL/TM-2013/416, Oak Ridge National Laboratory, Oak Ridge, TN (2013)

[13] J. Risner, D. Wiarda, M. Dunn, T. Miller, D. Peplow, B. Patton, Production and Testing of the VITAMIN-B7 Fine-Group and BUGLE-B7 Broad-Group Coupled Neutron/Gamma 


$$
15^{\text {th }} \text { ISRD }
$$

Cross-Section Libraries Derived from ENDF/B-VII.0 Nuclear Data, Technical Report ORNL/TM-2011/12, Oak Ridge National Laboratory (2011)

[14] K.G. Field, I. Remec, Y. Le Pape, Perspective on Radiation Effects in Concrete for Nuclear Power Plants - Part I: Quantification of Radiation Exposure and Radiation Effects, Nuclear Engineering and Design (to be published)

[15] Y. Le Pape, K.G. Field, I. Remec, Perspective on Radiation Effects in Concrete for Nuclear Power Plants - Part II: Perspective from Micromechanical Modelling, Nuclear Engineering and Design (to be published)

[16] A.H. Fero, Use of SSTRs and a Multi-Component Shield Assembly to Measure Radiation Penetrating the Reactor Biological Shield in the Presence of Radiation Streaming from Other Sources, ASTM STP 1398, 156-163 (1999) 